Nilza Azevedo Souza' Maria Eneida Matos da Rosa ${ }^{2}$

\section{Caio Fernando Abreu: das redes sociais às salas de aula}

\section{Caio Fernando Abreu: from social media to the classroom}

\section{Resumo}

O presente artigo intitulado "Caio Fernando Abreu: das redes sociais ás salas de aula" tem como objetivos analisar e compreender as influências dos novos meios tecnológicos sobre a literatura e como a questão ocorre, buscando sugerir um equilíbrio entre o físico e o virtual em sala de aula. A pesquisa em questão, também, examina os motivos de Caio Fernando Abreu ser um dos escritores mais populares em divulgações nas redes sociais e investiga se os leitores sentem-se motivados em saber mais a respeito de outras obras do autor. Este estudo salienta, ainda, a importância de se explicar aos estudantes os modos corretos de se publicar citações de outros autores nos novos meios de comunicação, explorando os malefícios e benefícios da divulgação da literatura nesses. A pesquisa demonstra, por fim, como se utilizar desses novos modos de disseminação para incentivar a leitura dentro e fora de sala de aula, promovendo atividades que envolvam tanto a pesquisa na internet quanto em livros em sua forma física, baseadas na grande recorrência aos textos de Caio Fernando Abreu.

Palvras-chave: Caio Fernando Abreu. Redes sociais. Literatura.

\begin{abstract}
This article named "Caio Fernando Abreu: from social media to the classroom" aims to analyze and comprehend the influences of new technological means of communication concerning literature and how it occurs, looking forward to suggest a balance between the real and the virtual in the classroom. Also, this research analyzes the reasons why Caio Fernando Abreu is one of the most popular writers disseminated in social medias and it examines if the readers feel motivated to know more about the author's work. Furthermore, this research reinforces the importance of instructing the students about the correct way to publish quotes from other writers through new means of communication, exploring the positive and negative effects of sharing literature this way. Finally, this study shows how to use those new means of dissemination to motivate the reading inside and outside the classroom, using activities that involve the internet-based research just as well as the research in real books based on the vast incidence of Caio Fernando Abreu's work.
\end{abstract}

Keywords: Caio Fernando Abreu. Social network. Literature 


\section{Introdução}

O artigo intitulado de "Caio Fernando Abreu: das redes sociais à sala de aula” tem como objetivo examinar a influência das redes sociais na Literatura, buscando definir, ainda, quais os motivos de identificação do leitor com as questões exploradas nos trechos dos textos de Caio Fernando Abreu. Pretende-se, pois verificar se esses se interessam ao ponto de pesquisar mais a respeito do autor e ler seus textos de forma completa e qual a importância de se recorrer aos novos meios tecnológicos, demonstrandose os pontos negativos e positivos do tema.

É notável que as redes sociais são grandes impulsionadoras de tendências no mundo atual, no qual todos estão rodeados pela tecnologia, criando uma espécie de sistema em que os indivíduos são agentes ativos na construção de novos saberes. Pelo exposto, a Literatura Contemporânea Brasileira não poderia ser esquecida dessa realidade, sendo possível observar tal fato na grande disseminação e divulgação de trechos de diferentes textos de Caio Fernando Abreu em determinados meios de comunicação atuais. $\mathrm{O}$ ideal é chamar a atenção dos alunos, no ambiente escolar, para algo com que já estejam familiarizados, como as obras literárias de determinados autores que se encontram tão vinculados às redes sociais. A importância da questão levantada é a de que é possível que adolescentes de Ensino Médio se interessem pela Literatura Brasileira, pois é algo ao qual estão expostos todos os dias quando acessam seus facebooks e twitteres. Portanto, por meio da utilização da internet e da divulgação de Caio Fernando Abreu nos meios tecnológicos de comunicação, é possível que se chame a atenção de adolescentes para a Literatura Contemporânea produzida no Brasil, demonstrando que tais questões lhe farão refletir de alguma forma a respeito de si mesmo e do mundo ao seu redor.

No primeiro momento, recorreu-se a obras que explicassem a trajetória do livro até o presente momento, que foram descritas de forma complementar por Regina Zilberman e Alberto Manguel. Em seguida, a pesquisa tornou-se mais ampla, pois se acreditou necessário explorar e definir os conceitos dos meios tecnológicos, o que resultou em literatura específica do assunto discorrido pelos estudiosos Pierre Lévy e Umberto Eco. Após a reflexão causada pelas primeiras análises, chegou-se a conclusão de como moldar a pesquisa para implantação no ambiente escolar, recorrendo-se aos estudos de Regina Zilberman e Marisa Lajolo.
Por fim, o tema escolhido teve o propósito de abranger uma realidade que faz parte do cotidiano escolar atual. A recorrência aos meios tecnológicos é cada vez mais notável e as escolas precisam estar prontas para as modificações, sem esquecer um de seus papeis principais de influenciadora da leitura. É necessário encontrar o equilíbrio correto entre o físico e o virtual e por isso, a pesquisa ressaltou mais uma vez o objetivo principal da escola que é o de formar cidadãos conscientes.

\section{Das tabuletas ao hipertexto}

"Toda a obra de um homem, seja em literatura, música, pintura, arquitetura ou em qualquer outra coisa, é sempre um auto-retrato; e quanto mais ele se tentar esconder, mais o seu caráter se revelará, contra a sua vontade."

Samuel Butler

Este capítulo visa à compreensão da evolução da leitura, por meio da observação e análise da popularidade do escritor Caio Fernando Abreu nos atuais meios de comunicação: as redes sociais. Demonstrando de forma resumida, porém detalhada o trajeto e relação da leitura/leitor e como a revolução tecnológica influenciou nos novos modos de divulgação e disseminação da Literatura Contemporânea Brasileira. Dentre os autores do período, é inegável que Caio Fernando Abreu é um dos destaques, por diversos motivos que serão explorados ao longo dessa pesquisa.

Os primeiros registros da escrita foram encontrados por arqueólogos, na antiga Babilônia, localizada onde, atualmente, encontra-se o Iraque. Tais documentos datados, aproximadamente, do quarto milênio a.C. eram produzidos em placas de argila moldadas como páginas de um livro. Nessas estavam informados valores de mercadorias, pertences e outros fatores ligados ao comércio e economia da época. Portanto, a escrita surgiu como necessidade de deixar registrado algo que a memória, por ser limitável, não conseguia transmitir ou guardar em sua completude. Conforme artigo "Da internet a Gutenberg" (1996) de Umberto Eco, a escrita foi idealizada com a intenção de "permitir ao ser humano lembrar o que de outra forma poderia esquecer."

Após isso, o homem se descobriu possuidor de algo que poderia modificar a própria história e ser passado adiante, independentemente de mensageiro, tempo ou espaço. Era algo que trazia uma espécie de poder aos humanos, que talvez os aproximasse dos Deuses, pois, de acordo com o que Alberto Manguel (1996, p. 207) cita no 
livro Uma história da leitura: "desde os primeiros vestígios da civilização pré-histórica, a sociedade humana tinha tentado superar os obstáculos da geografia, o caráter final da morte, a erosão do esquecimento." A possibilidade de poder comunicar-se por meio da escrita, resultou em algo extremamente útil para todos os seres racionais.

A princípio foram produzidos livros-texto, de acordo com as descobertas dos mesmos arqueólogos. Esses eram chamados de tabuletas escolares, por terem essência educativa, sendo encontrados nas casas de famílias aristocratas da época que preparavam seus filhos para tornarem-se escribas ${ }^{3}$. Tais profissionais eram ensinados a respeito da escrita, da produção das placas de argila e de como a documentação dos fatos deveria ser realizada. Portanto, era proibido àqueles menos abastados que participassem ativamente dessa espécie de revolução.

Alguns anos se passaram e a escrita evoluiu, tornando-se cada vez mais um sistema complexo de sinais e símbolos que foi utilizada pelos filósofos na Grécia Antiga. Entretanto, já não se produziam placas de argila e os pensamentos eram transcritos em uma espécie de folha de papel chamada papiro ${ }^{4}$. Ainda assim, os manuscritos dos filósofos eram acessíveis somente aos nobres, tendo em vista que a população não sabia ler, já que o fato não parecia interessante para os governantes, pois se a civilização tivesse acesso aos questionamentos dos filósofos, poderia passar a lutar por seus direitos, em vez de apenas aceitar os deveres, como descreve Eco (1996): "o livro poderia distrair as pessoas de seus mais importantes valores, encorajando informações desnecessárias, livre interpretação das Escrituras, curiosidade insana."

Na Idade Média, os rolos de papiro foram substituídos por pergaminhos ${ }^{5}$ e, logo em seguida, pelo códex ${ }^{6}$, de aparência muito similar ao que se conhece como o livro atualmente, facilitando a manipulação e consumo. Entretanto, a leitura era restrita ao clero e aos poucos alfabetizados, sendo absolutamente controlada pela Igreja que decidia o que

3 Profissionais capacitados para redigir normas de determinada população. Podendo, ainda, executar funções de contador, secretário, copista ou arquivista.

4 Espécie de folha, precursora do papel, obtida por meio de uma planta, usada para a escrita durante a Antiguidade.

5 Técnica que aproveitava pele de carneiro para fixar material escrito. (ZILBERMAN, 2001, p. 62).

6 Manuscritos gravados em madeira, muito parecidos com o livro. devia ou não ser publicado. As únicas bibliotecas e escolas daquela época localizavam-se nas próprias Abadias, Mosteiros e Igrejas, para que se pudesse ter a fiscalização do que seria publicado para a sociedade medieval. Para o clero, era imprescindível ter o controle sobre as Escrituras e o modo como seriam transferidas, sem que os fieis pudessem fazer quaisquer tipos de questionamentos quanto ao seu conteúdo, sendo educados somente pelas imagens que rodeavam os ambientes religiosos. Sem contar que era a forma de dominar os burgueses que não tinham acesso à leitura, conforme defende Eco (1996), denominando a situação de "divisão cultural":

entre aqueles que eram capazes de ler manuscritos e, portanto, trabalhar criticamente com assuntos religiosos, científicos ou filosóficos, e aqueles que eram educados apenas pelas imagens da Catedral, escolhidas e produzidas por seus mestres, os poucos alfabetizados.

Após alguns anos, as primeiras Universidades surgiram na Europa e com isso, as ideias Renascentistas passaram a combater o que era decretado pela alta sociedade e clero. Os filósofos do período buscavam a revolução e mudança dos ideais medievais, possibilitando uma espécie de poder aos burgueses. Nesse período a leitura passou a ser algo praticamente acessível aos menos abastados, se não por livros, pelo menos, de forma oral, o que ampliou o comércio livreiro e aumentou a quantidade de leitores. Porém, a Igreja ainda tentava manter-se no controle de o que era publicado na época, principalmente, durante os conflitos religiosos que ocorreram no período da Contra Reforma. Sendo assim, conforme explicita Regina Zilberman (2001, p. 22) na obra Fim do livro, fim dos leitores:

[...] a Igreja reage aos perigos da heresia religiosa com a reativação do Tribunal do Santo Ofício e a publicação, em 1564, do Index Librorum Probitorum, rol de textos interditados e apartados dos fieis, se não queimados em praça pública.

Em outro momento, um pouco depois desse período em que os livros passaram a ser mais disseminados, ainda eram escritas histórias das civilizações de forma didática e ideologias da filosofia. Entretanto, o objeto deixou de ser acessório de controle da população e combate aos governos, para trazer ao leitor uma espécie de fuga do mundo real, especificamente para as mulheres que viviam em casamentos hipócritas, por mera convenção da sociedade. A literatura foi substituindo, cada vez mais, as artes plásticas e o teatro e "[...] se tornando predileta de diferentes segmentos de público, como crianças e mulheres, até 
então negligenciados e que se tornaram o alvo principal de escritores e editoras" (ZILBERMAN, 2001, p. 23). A leitura era reconfortante para o sexo feminino, pois a sensação de que em algum lugar do mundo, alguma pessoa estava vivendo aventuras apaixonantes com as quais ela sempre sonhara, despertava esperanças a respeito de seu cotidiano. Entretanto, essas histórias tornavam-se perigosas para essas mulheres que, conforme a tese de Zilberman (2001, p. 32), eram "[...] iludidas pela promessa de felicidade contida em obras de ficção, acaba[vam] abatidas pela fantasia."

Nessa mesma época, era comum que a leitura fosse algo a ser dividido em momentos de descanso ou de diversão nas cortes das capitais. $\mathrm{O}$ ato de ler tornou-se algo prazeroso e mesmo, arma de sedução tanto para mulheres como para homens, de acordo com a descrição de Zilberman (2001, p. 29) nos seguintes trechos: "Em Razão e sensibilidade, são recorrentes as cenas domésticas em que os adultos leem, em voz alta e uns para os outros" e, na mesma página, a escritora defende que "os pares amorosos se formam em resposta ao modo de ler do parceiro masculino", tendo em vista que "os livros aproximam as pessoas e motivam o despertar da paixão."

Ao longo dos séculos, a educação foi decretada como direito de todos os cidadãos e, com isso, houve um crescimento considerável na produção de livros e propagação da leitura que continuou a carregar sua principal característica de envolver o leitor em realidades paralelas e diferentes das suas, nas quais poderia reconhecer-se ou descobrir quem gostaria de ser. Demonstrando que o ato de ler traz questões de interioridade e não apenas decodificação das palavras que rodeiam a sociedade em seu cotidiano. Essas são algumas das questões pelas quais a leitura evoluiu ao ponto de acompanhar a chamada revolução tecnológica, em que todas as civilizações modernas encontram-se dependentes do funcionamento de máquinas.

Atualmente, é extremamente difícil encontrar uma família que não possua, pelo menos, uma televisão ou computador, ou ambos. Tal mudança na sociedade afetou, também, o modo como a literatura é propagada, já que a internet ${ }^{7}$ é o ponto central de comunicação da sociedade moderna. É comum, cada vez mais, ver edito-

7 Conjunto de redes em escala mundial em que milhões de computadores são conectados por protocolo específico. ras recorrendo às mídias digitais ${ }^{8}$ para realizarem divulgações de novos e antigos títulos, tendo em vista que essa ferramenta é capaz de fazer com que o público interessado tenha acesso aos mais diversos tipos de informações. Como deixou claro Eco (1996): "estamos caminhando para uma sociedade mais liberada na qual a livre criatividade co-existirá com a interpretação textual.”

Tal evolução da leitura resultou em uma acessibilidade quase que igualitária entre as diversas classes da sociedade atual, se não pelo empréstimo de livros em bibliotecas públicas, pela disseminação dos mais variados textos econtrados na internet, sendo a tela do computador o transmissor de diferentes realidades e mundos, como em um livro na forma de palavras e páginas. Essa tecnologia possibilita ao leitor liberdade para ler o texto de forma mais rápida e prática, como defende Eco (1996), em seu artigo:

Hoje há hipertextos. Em um livro tem-se que ler da esquerda para a direita (ou da direita para a esquerda, ou de cima para baixo, de acordo com diferentes culturas) em uma forma linear. Pode-se saltar páginas, pode-se - já alcançada a página 300 - voltar para checar ou reler algo na página 10 - porém isso implica em trabalho, digo, trabalho físico. Ao contrário, um hipertexto é uma rede multidimensional onde cada ponto ou nó pode, potencialmente, ligar-se a outro.

Portanto, é possível perceber que o leitor envolvese, cada vez mais, com a tecnologia, agregando uma gama de diferentes saberes e informações que se realizam na forma de blocos textuais, nos quais palavras, imagens e sons envolvem-se com a finalidade de impulsionar a participação ativa na absorção do conhecimento. Criando uma rede em que cada ponto pode conectar-se a outro sem que haja necessidade de interesse prévio do leitor. Já que os textos estão interligados e pequenos trechos podem levar a pesquisas da extensa bibliografia de qualquer autor, sendo notável que o aprendizado é mais duradouro e transmissível, conforme afirmam os defensores e simpatizantes do hipertexto 9 .

De acordo com o trajeto que se demonstrou ao longo do capítulo, a leitura evoluiu de um patamar em

8 Suporte ou veículo da mensagem. O impresso, o rádio, a televisão, o cinema ou a Internet, por exemplo, são mídias (LÉVY, 2000).

9 Rede de nós de imagens, sons ou textos, cuja configuração permite uma leitura não-linear e inter-relacionada (LÉVY, 1999). 
que não era acessível a todos até chegar ao ponto em que passou a ser divulgada, facilmente, nas mídias digitais. $\hat{\mathrm{E}}$ comum que os usuários dos novos meios de comunicação, denominados de redes sociais ${ }^{10}$, utilizem desses espaços para dividir gostos pessoais com amigos e amigos de amigos, mesmo que de forma indireta. Entre esses, existem ainda perfis dedicados à Literatura Contemporânea Brasileira, nos quais são publicados trechos de textos de autores escolhidos ao gosto do "criador" da página. É possível perceber que a preferência pelo estilo citado, realiza-se pela descrição dos centros urbanos e seus problemas de desigualdades sociais, violência, solidão, angústias, perturbação e vergonha dos próprios sentimentos que, por vezes, podem não ser convencionais. Por tais motivos, a leitura não perdeu sua essência de fuga da realidade e causadora de reflexão a respeito de si mesmo, do mundo e da relação entre os dois, apesar de estar sendo observada com novos olhares e de diversos modos, após a revolução tecnológica.

\section{Dos livros às redes sociais}

Após o alcance da literatura às redes sociais, a atenção dos mais diversos tipos de leitores assíduos por trechos que descrevem sentimentos com os quais já lidaram ou talvez não saibam lidar, pareceu aumentar. Entre os autores mais populares dessa nova forma de se incentivar a leitura, encontra-se Caio Fernando Abreu, jornalista, dramaturgo, escritor e profundo entendedor das confusões e sentimentos humanos, que buscou descrever da forma mais pura possível as questões do ser em relação a si mesmo e a incapacidade de responder determinados questionamentos básicos que todas as pessoas se fazem em algum momento de suas vidas. A facilidade com que os internautas ${ }^{11}$ encontram trechos dos textos do escritor para publicar em suas páginas na internet pode ser explicada pelo motivo de que, como cita o pesquisador Bruno Souza Leal (2002, p. 47), no livro Caio Fernando Abreu, a metrópole e a paixão do estrangeiro: "o que seriam contos podem ser também momentos, trechos, partes, capítulos de um romance aberto, desossado, partido em uma estrutura clássica: um romance em ruínas."

\footnotetext{
${ }^{10}$ Estrutura social composta por pessoas ou organizações, conectadas por um ou vários tipos de relações, que partilham valores e objetivos comuns.

${ }^{11}$ Usuário da internet que a utiliza de maneira simples e ágil.
}

O escritor está presente em todos os tipos de redes sociais atuais, tais como facebook ${ }^{12}$ e twitter ${ }^{13}$, sendo "compartilhado" por diferentes leitores de distintos gêneros, classes, idades, personalidades e outros. Tal fato ocorre por essas pessoas dividirem as mesmas sensações que são tão comuns aos humanos e que Caio Fernando Abreu descrevia com uma espécie de maestria por vezes suave, por vezes rude. A atualidade do autor é tão perceptível que no aniversário de dez anos de seu falecimento, ocorreu em Porto Alegre, um evento chamado de Semana Caio F, no qual o Coordenador Luciano Alarbase afirmou que o escritor "nunca escreveu para impressionar literariamente nenhum leitor. Ele queria o coração, o fígado, a assombração do leitor. Essas coisas não perdem o carimbo de validade."

$\mathrm{O}$ autor fazia descrições da atualidade na qual se encontra a sociedade contemporânea, após diversas mudanças ao longo dos anos, descrevendo-a do modo como a percebia, sem preocupar-se com pormenores ou possíveis julgamentos. Caio Fernando Abreu realizava uma espécie de estudo das angústias e confusões intrínsecas ao ser humano desde os princípios. Buscando traçar, ainda, quais as influências da sociedade moderna sobre tais sentimentos e realizava reflexões a respeito da interioridade que alguns buscam esconder ou camuflar, ocupando lugar próprio como escritor de uma nova geração, tendo como inspiração um mundo de sensações. Conforme cita Graça Paulino (2002, p. 8), no prólogo do livro Caio Fernando Abreu: a metrópole e a paixão do estrangeiro: “[...] a câmara de Caio constrói cenas urbanas de desejos errantes, de gestos sem retorno, numa busca de identidade que se mostra vã e entretanto não cessa."

A popularidade de Caio Fernando Abreu pode ser explicada pela facilidade com que conseguiu, em seus textos, explorar e explicar a forma como se sentia. Seus contos não demonstram somente o modo como enxergava determinadas questões, o escritor conseguia descrever tudo pelo ponto de vista do ser comum, que vive o cotidiano apressado das grandes metrópoles e ainda tem tempo para realizar reflexões a respeito de si mesmo. É possível observar tais características, por exemplo, no

\footnotetext{
${ }^{12}$ Considerada a maior rede social da atualidade, desenvolvida em 2004 por Mark Zuckerberg.

${ }^{13}$ Rede social na qual o usurário tem 140 caracteres para compartilhar atualizações com os amigos cadastrados, desenvolvida em 2006 por Jack Dorsey.
} 
conto "Amor e desamor", em que uma mulher se apaixona rapidamente por um homem no ônibus e passa a refletir a respeito de si mesma e do sentimento que surgiu pelo passageiro ao seu lado. De acordo com o crítico literário Bruno Souza Leal, o escritor descrevia tais tipos de cenas pelo fato de que:

Na metrópole contemporânea, são tantas as referências, é tão grande o mundo e são tantas as formas de apreendê-lo, que qualquer tentativa de uma cristalização se torna um exercício de fé, crença, ficção. Num mundo em movimento (s), o eu se fragmenta e o amalgamento desses cacos exige um "projeto reflexivo" constante. (LEAL, 2002, p. 43)

É certo que o escritor falava diretamente ao seu leitor, criando uma espécie de intimidade, como se fosse um amigo próximo dando conselhos, Caio Fernando Abreu conversa diretamente com "você". Manguel (1996, p. 207) descreve essa relação como o ato de que "o escritor era um fazedor de mensagens, criador de signos, mas esses signos e mensagens precisavam de um mago que os decifrasse, que reconhecesse seu significado, que lhes desse voz. Escrever exigia um leitor." Esse é um dos motivos de ser tão comum encontrar trechos de contos do escritor na internet, o fato de que Caio não tinha como objetivo maravilhar ninguém fazendo uso de vocabulário difícil ou inventar histórias complexas que confundiam ainda mais a cabeça do leitor. $\mathrm{O}$ autor queria ser o refúgio, o ombro amigo, o psicólogo que faz refletir e entender, ou não, os motivos de se estar no mundo.

É perceptível a facilidade que o autor tinha para desenhar o cotidiano comum, por vezes banal, da sociedade. Caio construía imagens como um pintor que traceja cada detalhe de uma paisagem, montando perfis próprios e reconhecíveis, com os quais a identificação de quem observa é quase que imediata. O escritor escolheu, ou apenas tinha o dom, de envolver o leitor em uma teia de retratos, fatos, acontecimentos de sua própria rotina entediante e apressada dos centros urbanos. Escolheu explorar questões, descrever simples acontecimentos como uma manhã na vida de um casal que não sabe se ainda existe amor na relação, na tristeza, confusão e loucura pelo homem abandonado por "Ana", na quase quarentona que ainda acredita em "happy-ends cinderelescos", no adolescente cheio de dúvidas a respeito de sua sexualidade. Descrevia "você" em momentos de tristeza ou felicidade, cômicos ou trágicos, demonstrando "as partes banais do mundo real [...] citações de outros textos, indicação de lugares, gestos, objetos comuns - estão soltas, jogadas aqui e ali, não integram um rosto definido, podem ser de todo mundo." (LEAL, 2002, p.61)

Caio foi o homem das mil faces e talvez, por esse motivo, entendesse tão bem as angústias e alegrias que se unem dentro de cada um. Foi o menino Caio que brincava nas ruas de Santiago, sempre deixando sua imaginação fluir ao lado de seus irmãos e amigos. $\mathrm{O}$ adolescente Caio que se sentiu confuso e oprimido por ser "diferente" dos outros e fugiu para a cidade grande, para se encontrar, se entender. $\mathrm{O}$ homem Caio que estudou as Letras e as Artes, mas abandou as duas Faculdades para dedicar-se somente a sua escrita, ao seu modo de enxergar as coisas e as pessoas. O Caio que foi em busca do mundo, do estrangeiro, das diversas realidades que existiam em um só planeta. O amável, o confuso, o angustiado, depressivo, feliz, completo e absurdamente apaixonado pela vida. O escritor que sofreu com a AIDS, aceitou a doença, buscou paz em seu resto de vida e ao falecer, deixou um legado, uma herança e amor daqueles que mesmo sem conhecê-lo, tinham a certeza de serem seus amigos íntimos. $\mathrm{E}$ como cita Zilberman (2001, p. 112) retomando Barthes: "cada autor tem afiançada uma sobrevida que ultrapassa a de seus herdeiros." Tornando-se, assim, o Caio das redes sociais, que está fazendo com que várias pessoas se apaixonem pela Literatura Contemporânea Brasileira.

Por fim, é possível perceber que o autor se fez, e ainda se faz notável por todos os motivos expostos. Caio Fernando Abreu é extremamente querido e procurado, mesmo após sua morte. Seus textos fazem com que o leitor se envolva ao ponto de realizar reflexões a respeito de si mesmo e do mundo que o rodeia. É como se o autor tivesse a capacidade de escrever fatos que ocorrerão com qualquer pessoa, seja de qualquer classe social, idade, crença, seja quem for. A leitura evoluiu ao ponto de acompanhar a revolução tecnológica e com isso, a literatura e o modo como é disseminada, também se modificou. Hoje, o acesso aos mais diversos tipos de texto é mais fácil e rápido e Caio tem lugar especial no coração desses novos leitores pela facilidade com que demonstra se importar com a profunda interioridade de cada um. Caio Fernando Abreu é "comprometido com a loucura, com o delírio, com a quebra do real e com a outra versão do "normal", o narrador não acena com julgamentos morais radicais, com condenações inapeláveis. Ele é, sempre, a última instância, solidário." (LEAL, 2002, p. 54) 


\section{Pessimistas céticos - Os malefícios}

O hipertexto, ao permitir que o leitor escolha sua própria trilha dentre um conjunto de possibilidades, dissolve a rigidez fundamental em que se baseia nossa teoria e práticas críticas.

George P. Landow

Essa nova forma de se publicar Literatura tem suscitado diversos tipos de debates desde que a revolução tecnológica tornou-se cada vez mais presente e demonstrou-se uma das novas responsáveis pela divulgação de obras literárias. Como todos os casos polêmicos, a questão possui otimistas defensores e pessimistas céticos. É claro que a disseminação dos mais diversos tipos de textos na internet tem tanto benefícios como malefícios. Mas até que ponto o uso das novas mídias digitais é seguro para se compartilhar obras literárias? Até que ponto os livros podem ser substituídos por e-books ${ }^{14}$, redes sociais ou outros dispositivos tecnológicos advindos da praticidade que a sociedade atual exige? Existem diversos outros questionamentos que causam reflexões a respeito do modo como se está fazendo a literatura no presente momento e como essa será, ou já está sendo, influenciada pela propagação sem controle na internet.

Uma das questões a se pensar é a respeito da chamada ausência de autoria. É possível exemplificar a situação pelos trechos das obras de Caio Fernando Abreu que são compartilhados constantemente nas redes sociais. A princípio, esses são identificados como do autor e dispostos entre aspas, como é comum e deve ser feito em todas as citações. Todavia, ocorrerá um momento em que alguma pessoa não terá essa consciência ou agirá de má fé, publicando um trecho qualquer como se fosse seu e é a partir dessa ocasião que a ausência de autoria acontecerá. Pelo fato de o autor não ser citado, acaba se perdendo no desejo do outro de dividir sem controle algum, o que não foi escrito por si. O que contraria a definição de autor conceituada pela linguista Eni Orlandi (1996, p. 68) em Interpretação: autoria, leitura e efeitos do trabalho simbólico, quando afirma que "o autor é o princípio de agrupamento do discurso, unidade e origem de suas significações. O que o coloca como responsável pelo texto que produz."

\footnotetext{
${ }^{14}$ Livro em formato digital que pode ser lido por meio de equipamentos eletrônicos.
}

A palavra chave do conceito abordado por Orlandi é responsabilidade, pois cada um é responsável por suas ações e por aquilo que cria, sendo considerada falta de respeito publicar o que não é seu, sem as devidas considerações ao "dono". Entretanto, é importante salientar que a figura do autor só foi estabelecida no fim da Idade Média, quando a industrialização e crescimento do mercado literário começaram a delinear-se com traços mais fortes, tendo em vista que os tipógrafos se consideravam donos dos livros que vendiam, sendo substituídos, mais tarde, por editores e livreiros que reclamavam o poder do que publicavam. Por tal motivo, existem diversas obras, como as mitologias gregas, por exemplo, que não apontam um escritor como responsável pelo desenvolvimento do enredo milenar.

Para maior aprofundamento da questão, o tema é explicado, também, pelo crítico literário Antoine Compagnon (2007, p. 146), no livro O trabalho da citação quando explicita que existem três formas de se entender essa relação de "pertence" entre o que foi escrito, o autor e o leitor. Primeiramente, existe a ideia de posse que "é imaginária, ao nível de uma fantasia de fusão em que o sujeito participa do dentro e do fora de si (pessoa, olhos) e do outro (autor, discurso)", podendo ser exemplificada por um indivíduo que compra um livro e acaba por se reconhecer e se envolver com o que é proposto pelo discurso do autor, ocorre uma espécie de construção conjunta em que o autor depende do leitor e vice-versa.

Em segundo lugar, acontece a apropriação em que "o sujeito parte em busca de si mesmo, como de um outro, à procura de sua identidade entre os objetos que o circundam. [...] Deixe espaço entre você e o livro, é esse espaço que lhe permite fazê-lo seu." (COMPAGNON, 2007, p. 147), ou seja, as reflexões causadas por aquele discurso são absolutamente relativas a cada leitor, dependente de seus conhecimentos prévios de mundo, porém é preciso ter consciência de que nem tudo o que acontece naquele discurso, pode aplicar-se à vida real, por isso Compagnon propõe o espaço entre obra e leitor, visando uma relação saudável entre ambos.

Por último, de acordo com o crítico, existe a noção de propriedade em que deve ocorrer uma "separação entre o autor (instituição ou pessoa moral, consolidação recursiva da variedade dos sujeitos) e o livro (também ele instituição e pessoa moral, mercadoria)" (COMPAGNON, 2007, p. 147). Ou seja, um mesmo es- 
critor pode discorrer a respeito de diversos temas, como é o caso de Caio Fernando Abreu. Não é só por que o autor escrevia a respeito de amor e delicadezas de paixões, que não podia ser mordaz e rude em alguns de seus textos também. É preciso entender que a maioria dos grandes autores, não tratará a respeito do mesmo assunto sempre.

Tais casos, se não forem compreendidos de forma correta pelos leitores, conforme as conceituações de Compagnon, podem ser considerados como plágios, mesmo que não intencionais. A palavra vem do latim plagiarus, que significa roubar, sendo considerado crime pela Lei de Direitos Autorais 9.610 de 19 de fevereiro de 1998, que aborda a questão como violação grave à propriedade intelectual e aos direitos autorais, além de agredir frontalmente a ética e ofender a moral acadêmica, conforme afirma Randal Fonseca, no artigo "Expropriação da propriedade intelectual", portanto não plagiar deveria ser uma questão de honra.

Um dos primeiros registros de plágio ocorreu no século XVII quando Miguel de Cervantes teve sua obra $O$ engenhoso fidalgo Dom Quixote de la Mancha copiada por Alonso Fernández Avellaneda, que produziu uma espécie de continuação do livro com as personagens que pertenciam ao imaginário de Cervantes, sem ao menos citá-lo. O caso não foi único e isolado e as cópias ilegais na literatura e artes em geral acontecem como algo comum desde o período em que os livros passaram a ser impressos e distribuídos com maior facilidade. O jornalista Jerônimo Teixeira (2006) revela, no artigo "Os ladrões criativos" para a Revista Veja que existem diversos registros de obras em duplicidade, tendo em vista que:

\begin{abstract}
Os exemplos seriam infindáveis. Shakespeare buscava material para suas peças em obras de Ovídio e Chaucer, em lendas italianas e crônicas históricas inglesas, entre outras várias fontes. Do pensador francês Pascal, já foi dito que escrevia com um volume dos Ensaios de Montaigne aberto na sua frente, tal a profusão de citações e apropriações que fazia daquela obra. $\mathrm{O}$ poeta francês Charles Baudelaire roubou alguns versos do americano Edgar Allan Poe. O brasileiro Gonçalves Dias decalcou sua famosa Canção do Exílio de um poema do alemão Heine.
\end{abstract}

Como discorrido, é comum encontrar os mais diversos tipos de trechos, não somente de contos de Caio Fernando Abreu, compartilhados nas redes sociais sem os devidos créditos, o que resulta em plágio. Como é pos- ário (a) do facebook, cita Caio Fernando Abreu, sem ao menos referenciá-lo da devida forma:

Figura 1- Imagem retirada do facebook para exemplificar a questão.

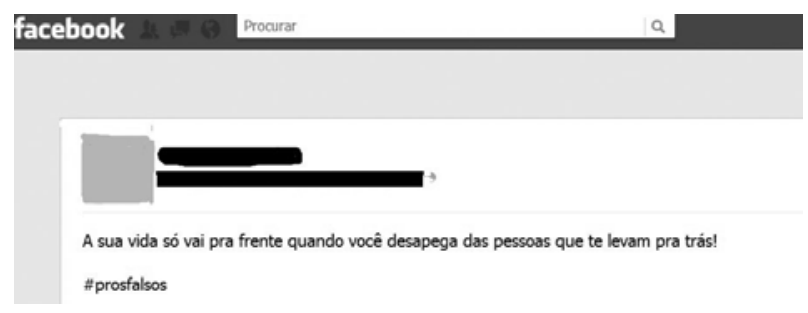

Fonte: Elaborado pelas autoras e extraído do facebook.

Os céticos pessimistas citados no começo do capítulo acreditam que a ausência de autoria e, por conseguinte, o plágio resultam em textos sem referências seguras. Com as novas tecnologias de publicação da Literatura atual, é possível encontrar os famosos pastiches que são definidos como imitações do estilo de outros escritores, chegando a confundir leitores, caso não se assumam a autoria. $\mathrm{O}$ fato pode ser exemplificado com alguns trechos de Caio Fernando Abreu divulgados nas redes sociais, pois é preciso perguntar-se se aquela citação é mesmo do autor e se foi algo produzido por alguma outra pessoa, sendo publicado como de Caio. Então, até que ponto é possível confiar que aquilo que está sendo divulgado no facebook ou twitter de alguém pertence mesmo àquele escritor?

O blogueiro ${ }^{15}$ Maykon Souza descreve a questão de forma sútil na crônica "Caio Fernando Abreu: o cara do facebook", quando relata uma situação vivida por ele ao conversar brevemente com uma jovem adulta a respeito do autor, em um shopping. Conta que estava concentrado na leitura de Onde andará Dulce Veiga?, quando a moça o interrompeu perguntando se Caio já tinha livros publicados, identificando-o como o "o cara que escreve coisas fofas. Ele fala de amor, esperança, sorriso. Coisas para valorizar a gente. Ele tem frases que se encaixam em todos os momentos da vida da gente." Maykon lê um trecho mais cru e menos sentimentalista da obra para a mulher que, sequer sabia que o autor já estava morto, tinha vários livros publicados e não escrevia somente a respeito das amenidades de uma vida apaixonada, terminando o texto com a seguinte frase: "Da próxima vez que estiver em público, puxo um Dostoiévski. Duvido que ele tam-

\footnotetext{
${ }^{15}$ Pessoa que escreve em blogs, que são sites pessoais nos quais seu "criador" publica artigos, crônicas, pensamentos e outros.
} 
bém tenha perfil fofo no Face." O relato leva a acreditar que Maykon encontra-se entre os pessimistas céticos que acreditam que a revolução tecnológica não deve ter envolvimento algum com a Literatura, pois a transforma em algo banal, em "Minutos de sabedoria" das redes sociais, como definido por ele.

O blogueiro aparenta crer que esses pequenos trechos disponibilizados na internet, acarretarão com o fim dos livros. A sociedade moderna pode recorrer aos mais diferentes meios tecnológicos para ler obras que, antigamente, somente eram impressas. Hoje existe o $e$ -book, sendo assim chamadas as digitalizações das obras que podem ser lidas em qualquer computador, celulares ou aparelho específico para leitura desses. Entretanto, até que ponto os aparelhos tecnológicos podem substituir a sensação de folhear um livro, sentir o cheiro da folha de papel reciclada ou passar os dedos pelos relevos da arte da capa? Eco (1996) acredita que "a chegada de novos dispositivos tecnológicos não tornam, necessariamente, obsoletos os velhos", ressaltando que "na história da cultura nunca ocorreu que alguma coisa tenha simplesmente destruído outra coisa. Alguma coisa mudou profundamente outra coisa." Portanto, a internet veio como uma maneira de aperfeiçoar a leitura, e não para substituir aquilo que já existe há séculos.

\section{Defensores otimistas - Benefícios}

Apesar dos malefícios expostos, é necessário ser um defensor otimista também e refletir a respeito dos benefícios que essas novas formas de comunicação levam ao despertar o interesse de adolescentes e jovens adultos pela Literatura Brasileira, considerada desde os primeiros anos escolares como "difícil", "complexa" e "entediante". A revolução tecnológica conduziu muitas melhorias para a sociedade atual, inclusive a facilidade com que uma simples informação pode ser encontrada de forma rápida nas páginas da internet destinadas às pesquisas. Já em 1996, Eco previa a praticidade desses novos recursos ao comparar as Enciclopédias usadas em sua época de infância aos buscadores eletrônicos, nos quais existe a possibilidade de ser guiado por hipertextos, defendendo que se pode:

navegar pela enciclopédia inteira. [...] ligar um evento registrado no começo com uma série de eventos similares ao longo do texto, comparar o começo com o final, perguntar pela lista de todas as palavras começando por A, perguntar por todos os casos nos quais o nome de Napoleão está vinculado com o de Kant, comparar as datas de seus nascimentos e mortes - em suma, [...] realizar as tarefas em segundos ou minutos.

Essa forma de "navegar" por redes que se conectam, abre uma possibilidade de mundos com os quais algumas pessoas não poderiam nem pensar poucas décadas atrás. As tecnologias encontram-se cada vez mais acessíveis para a população, mesmo às famílias de baixa renda e isso tem facilitado a disseminação de novos saberes. Pode-se exemplificar a situação pela divulgação da Literatura Contemporânea Brasileira na figura do autor Caio Fernando Abreu. Fica claro que é necessário tomar cuidado para não acreditar em tudo que é publicado nas redes sociais como algo absolutamente confiável, como já explanado anteriormente, porém é preciso entender como o fato tem abordado diretamente a grande maioria dos jovens leitores do país que acabam por se interessar em descobrir mais a respeito da obra e, também, da vida do autor.

No livro O que é virtual?, o filósofo Pierre Lévy (1999, p. 39) afirma que as leituras influenciadas pelas novas tecnologias "reaproximam-se daqueles do diálogo ou da conversação." Esse é um dos motivos que prende o leitor a um romance, conto, crônica ou qualquer outro gênero textual, é a sensação de que aquele enredo está dialogando com ele de alguma forma. No momento em que o leitor se reconhece no texto e sente-se um reprodutor daquela história, em vez de simples receptor, a Literatura cumpre seu papel que vem sendo auxiliado, no caso, pelas redes sociais no momento em que as pessoas compartilham seus interesses, sentindo-se ativas na divulgação de suas leituras favoritas.

Quando alguém se interessa em pesquisar mais a respeito de o que está sendo lido, acaba encontrando opções de diferentes textos dos autores. Pode-se exemplificar a questão por um adolescente que acessa seu $f a$ cebook após chegar da escola, reclamando de como a aula de Literatura foi entediante e se depara com um pequeno trecho, por exemplo, do texto "Ao simulacro da Imagerie" de Caio Fernando Abreu (2006, p. 23), no qual escreve que "como quem não desiste de anjos, fadas, cegonhas com bebês. Ilhas gregas e happy ends cinderelescos, ela queria acreditar." Esse mesmo adolescente que chegou do colégio, irritado com a aula de Literatura, passa a se interessar por aquele autor que foi devidamente referenciado no trecho publicado. Em seguida, abre uma página de 
busca e digita o nome completo do escritor, deparando-se com uma gama vasta de informações a sua escolha, à distância de apenas um clique que disponibilizará outra diversidade de apontamentos a respeito do autor, que terá as mesmas características, fazendo com que o estudante tenha acesso a distintos sites daquele em que sua busca começou, tendo em vista que "a tela informática é [...] o lugar onde uma reserva de informação possível vem se realizar por seleção, aqui e agora, para um leitor particular" (LÉVY, 1999, p. 41). Essa espécie de teia em que tudo parece conectado e levar a um caminho novo é definida como hipertexto, conceituado no livro Cibercultura de Lévy (2000, p. 56). Destaca, pois essa expressão como “constituído por nós (os elementos da informação, parágrafos, páginas, imagens, sequências musicais, etc.) e por links entre esses nós, referências, notas, ponteiros, "botões", indicando a passagem de um nó a outro."

Outra característica interessante do hipertexto é a de permitir que o sujeito busque o próprio conhecimento, sem depender de ordens de terceiros, como professores, familiares e outros, participando da construção do saber como um ser ativo e produtor de suas reflexões únicas. Tal situação abre espaço para ocorrências diversas, nas quais o leitor pode escrever um final diferente para um livro e publicar na internet, sem problema algum, contanto que realize as considerações pertinentes ao autor da obra na qual se inspirou, sendo que um hipertexto "pode transformar todo leitor em um autor", e ao contrário de o que muitos pensam "um hipertexto é finito e limitado, embora aberto a inumeráveis e originais perguntas", de acordo com as considerações de Eco (1996). Ou seja, esse texto aberto aos pontos de vista e apontamentos de cada leitor, não suporta todo e qualquer tipo de interpretação, pois é necessário que não se descontrua a essência daquele discurso.

Entretanto, existem as mais diferentes possibilidades de se expressar de acordo com o que é abordado naquela obra. Ainda usando de exemplo o texto "Ao simulacro da Imagerie" de Caio Fernando Abreu e o mesmo trecho citado anteriormente, é praticável que um indivíduo, para especificar: uma mulher, leia aquela pequena parte do conto que descreve a raiva de uma mulher ao ser abandonada por um homem, que nem mesmo amava, ao encontrá-lo na fila de um supermercado. Ela esbraveja, lembra-se dos momentos que passou ao lado dele e sente-se indignada pelo sujeito nem ao menos cumprimentá- pode fazer com que o leitor imagine uma situação diferente. A imaginação humana é algo ilimitável e produtora de diferentes realidades. Não é pelo fato de que aquela determinada mulher, imaginou que o discurso poderia se referir a uma adolescente que sofreu sua primeira desilusão amorosa, acabando por tornar-se empática pela dor da garota, que sua interpretação daquela passagem literária está equivocada, comparando-se com a de alguém que leu o texto por completo. Naquele contexto indicado, aquela interpretação era possível e, por isso, o hipertexto é um auxiliador na geração de outras percepções, fantasias e enredos. A beleza da Literatura na realidade atual está exatamente nesse ponto em que "o texto não é mais amarrotado, dobrado feito uma bola sobre si mesmo, mas recortado, pulverizado, distribuído, avaliado segundo critérios de uma subjetividade, que produz a si mesma." (LÉVY, 1999, p. 36).

Pode-se perceber que o hipertexto é um grande beneficiador na construção do conhecimento de diversos indivíduos. A partir do momento em que o sujeito se envolve com o texto e percebe a possibilidade de descobrir os mais diversos fatos, como por exemplo, curiosidades da vida do autor e até mesmo uma vasta bibliografia que jamais pensara existir, ele se transforma em um participante ativo na produção de seus novos saberes, podendo passá-los adiante com a certeza de que compreende aquele tema, pois realizou uma pesquisa profunda, lendo os mais distintos materiais disponíveis na rede. Entretanto, é preciso ter atenção ao que se está buscando, para que não se caia nas armadilhas de informações equivocadas ou falsas.

Por fim, como é comum de todo assunto, a questão tem tanto pontos positivos como negativos. Alguns dizem que a publicação de textos na internet acarretará a extinção dos livros impressos, e outros, já acreditam que a situação só traz benefícios, inclusive para as editoras que encontraram um canal para comunicação direta com seus consumidores. O principal objetivo da questão é entender que o novo nunca substitui completamente o arcaico. Ainda hoje, populações ao redor do mundo utilizam palavras originadas do latim sem ao menos saberem. Portanto, não é possível que as novas tecnologias modifiquem a impressão de livros. Usando o exemplo daquele mesmo adolescente que pesquisou mais informações a respeito de Caio Fernando Abreu, entende-se que ele chegará a um momento em que estará em uma Livraria, em uma tarde de domingo com seus pais e decida que 
quer comprar um livro do autor. Perguntará ao vendedor do local, que lhe oferecerá uma gama de opções, talvez o adolescente escolha um ou dois livros, talvez não escolha nenhum, mas terá a certeza de que existem obras impressas do autor, às quais pode recorrer quando for de seu interesse, consciente de que aqueles livros também escondem as mais diversas realidades que ele não poderá encontrar completamente nas redes sociais ou buscadores da internet.

Portanto, de acordo com Eco (1996): "livros continuarão indispensáveis não só para a literatura, mas em qualquer circunstância onde se precisa ler cuidadosamente, não apenas receber informação, mas também especular e refletir", salientando que "ler uma tela não é o mesmo que ler um livro, [...] em certos momentos, sinto-me insatisfeito e procuro uma forma de leitura mais relaxada e confiável." O artigo em que Eco realizou tais previsões já tem mais de dez anos e as Livrarias e Bibliotecas continuam repletas de pessoas e livros impressos, portanto suas previsões podem estar corretas e não há nada com o que se preocupar, apenas usufruir dessa nova forma de se disseminar a leitura, utilizando as ferramentas como incentivadoras e não, substituintes.

\section{Caio Fernando Abreu: das redes sociais às sa- las de aula}

\subsection{Como utilizar os meios tecnológicos em sala de aula}

Nem só de flores se pavimenta o ensino da literatura, nem é monólogo de autores estrangeiros a rudeza do golpe que a escola parece patrocinar ao pôr autores clássicos nas mãos dos alunos.

\section{Regina Zilberman e Marisa Lajolo}

Conforme exposto ao longo dos capítulos anteriores, a revolução tecnológica conquistou papel essencial na atualidade, onde se pode observar maior recorrência aos meios tecnológicos para a produção de novos conhecimentos. Evidentemente, o ambiente escolar foi afetado pela questão, assim como todos os outros, e busca adequar-se aos novos modos de geração de informações constantes, enxergando os novos meios de comunicação como aliados na construção das competências e habilidades dos estudantes.

Já faz alguns anos que diversas escolas buscam trabalhar com os meios tecnológicos da melhor forma, até mesmo para que o estudante não acabe por se entediar pela rotina de aulas copiadas do quadro negro e exercícios dos livros didáticos, e sintam-se participantes ativos ao pesquisarem e expressarem seu entendimento a respeito de tema devidamente guiado pelo professor. Então, por qual motivo não aproveitar tais ferramentas para fazer com que as aulas de Literatura sejam mais interessantes? Regina Zilberman e Marisa Lajolo (2009, p. 31) defendem, no livro Das tábuas da lei à tela do computador, que "o acesso à realidade virtual depende do domínio da leitura e, assim, esta não sofre ameaça nem concorrência. Pelo contrário, sai fortalecida por dispor de mais um espaço para sua difusão". Ou seja, o acesso às mídias digitais não fará com que os estudantes abandonem os livros, sendo perfeitamente possível realizar atividades equilibradas entre ambos.

Os adolescentes dessa nova geração são considerados como multiconectados, pois representam uma parte da população que acompanha a evolução tecnológica que se demonstra uma das principais essências das novas civilizações, conforme Eco (1996) descreveu em seu artigo ao dizer que "a nova geração é treinada para ler em uma velocidade incrível." É possível desenvolver atividades de leitura por meio de computadores, com os caminhos devidamente trilhados por educadores, tendo em vista à aprendizagem de ambas as partes, pois como já explicado, o hipertexto sempre traz uma nova informação.

A literatura pode e deve ser incentivada no ambiente escolar, de forma prazerosa, a fazer com que o indivíduo sinta-se confortável com o texto que tem nas mãos. Já faz algum tempo que o papel da escola deixou de ser o de controlar o que deve ser considerado como literatura ou não, para realizar o de incentivadora da leitura. É preciso que os educadores estejam dispostos a escutar o que o sujeito tem a acrescentar e não apenas obrigar a leitura de livros que são considerados do cânone literário. É importante que a leitura seja algo prazeroso e que considere a formação de seu leitor, seus conhecimentos de mundo e suas opiniões, pois é por meio do ato de ler que as mais diversas habilidades e competências são motivadas. O Plano Nacional do Livro e Leitura (PNLL) aborda a questão quando descreve os benefícios e importância da leitura, ao explanar que por meio dessa é:

[...] possível que, na sociedade da informação e do conhecimento, ele exerça de maneira integral seus direitos, participe efetivamente dessa sociedade, melhore seu nível educativo (em 
amplo sentido), fortaleça os valores democráticos, seja criativo, conheça os valores e modos de pensar de outras pessoas e culturas e tenha acesso às formas mais verticais do conhecimento e à herança cultural da humanidade. (PNLL, 2006, p. 25).

Conforme o objetivo exposto do PNLL é possível observar que é fundamental que os leitores sejam formados nos primeiros anos escolares e que as obras literárias sejam trabalhadas mais profundamente durante todo o ensino fundamental e médio, fazendo com que os estudantes tornem-se cidadãos engajados em seu papel de refletir a respeito do mundo do qual fazem parte, para que possam propor mudanças e melhorias. Portanto, se os meios atuais os quais os professores podem recorrer para fazer com que os alunos sintam-se interessados, são os tecnológicos, é preciso que o educador entenda o valor dessas ferramentas para que possa utilizá-las da melhor forma possível. Eco (1996) expõe a situação quando afirma que "hoje o conceito de alfabetização compreende várias mídias. Uma boa política de alfabetização considera as possibilidades dessas mídias todas. A preocupação educacional deve ser estendida ao conjunto das mídias."

Até mesmo o PNLL defende que a divulgação da literatura deve acontecer nos mais diversos meios de comunicação, entre eles: a internet, pois é fato que as redes facilitam o acesso a uma sucessão de informações pertinentes à aprendizagem do estudante. É necessário utilizar a tecnologia para transmitir o conhecimento de forma a acompanhar a realidade daquele aluno que está conectado às redes sociais. Acima de tudo, é preciso dar certa prioridade ao tema com a intenção de fazer com que os indivíduos sejam críticos o suficiente para ter a segurança de que aquela citação encontrada em seu facebook ou twitter pertence realmente ao autor ao qual estão ligadas. Para que tenham a noção de o que é plágio e quais as consequências que podem ocorrer quando alguém utiliza produções de terceiros e assume como seu algo que não lhe pertence.

Portanto, é importante que a escola esclareça aos alunos desde o ensino fundamental, como pesquisas devem ser realizadas e de qual forma as citações precisam ser referenciadas com o objetivo de que a produção dos primeiros trabalhos escolares dessa espécie seja realizada de maneira correta, dando o suporte necessário para que quando esses indivíduos ingressem em um curso superior, saibam agir de acordo com as normas. Ou até mes- mo quando decidirem publicar trechos de contos, novelas, crônicas ou outros que tenham achado interessante nos seus perfis das redes sociais, a fim de que, futuramente, não haja problemas em relação quanto à ausência de autoria em que os textos acabam por se perder em sua divulgação constante sem as referências necessárias.

\subsection{Redes sociais em sala de aula}

De acordo com o que foi explorado durante todo o desenvolvimento desse artigo, é necessário que os educadores utilizem os meios tecnológicos como ferramentas úteis e os conduzam para dentro de sala de aula, moldando-os de acordo com as competências e habilidades que deseja atribuir aos seus alunos. Se um professor de Ensino Médio tem acesso a, pelo menos, uma rede social, poderá perceber a grande recorrência aos textos de Caio Fernando Abreu e como adolescentes e jovens adultos são os principais leitores do autor nos meios de comunicação citados.

Já que um dos deveres do educador é incentivar a leitura, como definem Marisa Lajolo e Regina Zilberman (2009, p. 124) ao afirmarem que:

O professor, entendido como principal agente na introdução do indivíduo no mundo da escrita, ocupou-se da formação de leitores. E, assim, um sistema triangular tomou forma no decorrer da história brasileira, organizado em torno a esses ângulos - professor, escola e aluno -, sendo confiados aos dois primeiros uma tarefa e uma responsabilidade, e ao terceiro, uma obrigação.

Então, é importante que tal ação ocorra a modo de produzir leitores, sem lidar com a leitura como mera obrigação, com objetivos pré-determinados, no qual o aluno pensa somente em ser aprovado para o ano seguinte na escola ou em algum vestibular. A literatura não deve ser tratada como obstáculo, e sim como auxiliadora nas mais diversas questões tanto pessoais como escolares. Para que isso ocorra, o educador tem de pensar no que chama atenção daquele estudante, refletir por alguns momentos a respeito do que torna aquele adolescente confuso em um leitor sedento. E é exatamente por isso, que ocorre a necessidade de recorrer à popularidade das redes sociais e se aproveitar do que está sendo explorado.

Existe uma multiplicidade muito ampla de textos de Caio Fernando Abreu na internet, em que os trechos publicados na rede são extremamente acessíveis e chamam atenção do leitor de uma maneira especial. Tornando a citar o exemplo do adolescente que leu uma parte de um conto de Caio em seu facebook e com isso se inte- 
ressou em buscar mais informações a respeito do autor, é fato que em algum momento ele comentará a respeito do escritor com seu grupo de amigos e alguns deles, talvez, até já tenham ouvido falar do autor. É evidente que na sociedade capitalista e competitiva na qual esse adolescente está inserido, o que importa para algumas determinadas escolas é obrigar as leituras que são exigidas nos vestibulares, deixando de lado de lado seu papel de estimuladora e formadora de leitores ativos. Entretanto, é necessário que o educador explore os interesses de seu aluno, produzindo sujeitos que valorizem a literatura de seu país e até mesmo, quem sabe, venham a tornarem-se escritores.

Por fim, é necessário que o ensino literário se molde aos novos aspectos da sociedade tecnológica e torne-se satisfatório, levando em conta as opiniões e preferências dos estudantes. Para que a educação atual possa chegar a um equilíbrio no qual ocorra a formação de leitores ativos e transmissão dos saberes necessários a fim de que o aluno possa obter as habilidades e competências exigidas. Ao produzir um plano de ensino norteador no qual o educador leva a realidade dos alunos para a sala de aula, ocorre uma troca de conhecimentos na qual todos os envolvidos saem ganhando.

\section{Referências}

ABREU, Caio Fernando. Caio 3D: o essencial da década de 1980. Rio de Janeiro: Agir, 2005.

ABREU, Caio Fernando. Caio 3D: o essencial da década de 1990. Rio de Janeiro: Agir, 2006.

COMPAGNON, Antoine. O trabalho da citação. Minas Gerais: UFMG, 2007.

ECO, Umberto. Da internet a Gutemberg. 1996. Disponível em: $<$ http://www.inf.ufsc.br/ jbosco/InternetPort.html $>$. Acesso em 12 de mar. 2012.
FONSECA. Randal. Expropriação da propriedade intelectual. Disponível em: <http://www.historiaehistoria.com. $\mathrm{br} /$ materia.cfm?tb $=$ newsletter\&id=3>. Acesso em: 25 mar. 2012.

LAJOLO, Marisa; ZILBERMAN, Regina. A formação da leitura no Brasil. 3. ed. São Paulo: Ática, 2010.

LAJOLO, Marisa. ZILBERMAN, Regina. Das tábuas da lei à tela do computador: a leitura em seus discursos. São Paulo: Ática, 2009.

LEAL, Bruno Souza. Caio Fernando Abreu, a metrópole e a paixão do estrangeiro: contos, identidade de sexualidade em trânsito. São Paulo: Annablume, 2002.

LÉVY, Pierre. Cibercultura. 2. ed. São Paulo: Editora 34, 2000.

LÉVY, Pierre. O que é virtual? São Paulo: Editora 34, 1999.

MANGUEL, Alberto. Uma história da leitura. 2. ed. São Paulo: Companhia das letras, 2002.

ORLANDI, Eni Puccinelli. Interpretação: autoria, leitura e efeitos do trabalho simbólico. Rio de Janeiro: Vozes, 1996.

PLANO Nacional do Livro e Leitura. Disponível em: $<$ http://www.oei.es/fomentolectura/pnll_brasil.pdf $>$. Acesso em: 18 abr. 2012.

SOUZA, Maykon. Caio Fernando Abreu: o cara do face. 2012. Disponível em: <http://www.brasildefato.com.br/ node/8922\#.T3HXRFFdqXw.facebook>. Acesso em: 27 mar. 2012.

TEIXEIRA, Jerônimo. Os ladrões criativos. Revista Veja, 2006. Disponível em: <http://veja.abril.com. br/290306/p_130.html $>$. Acesso em: 25 mar. 2012.

ZILBERMAN, Regina. Fim do livro, fim dos leitores? São Paulo: Senac, 2001. 


\section{Para publicar na revista}

Universitas Humanas,

acesse $o$ endereço eletrônico www.publicacoesacademicas.uniceub.br. Observe as normas de publicação, para facilitar e agilizar o trabalho de edição. 